\title{
REFLEXÕES SOBRE A EDUCAÇÃO FÍSICA NO BRASIL: LEITURA E GINÁSTICA NA PRIMEIRA REPÚBLICA
}

\author{
REFLECTIONS ON PHYSICAL EDUCATION IN BRAZIL: \\ READING AND GYMNASTICS IN THE FIRST REPUBLIC
}

\author{
REFLEXIONES SOBRE LA EDUCACIÓN FÍSICA EN BRASIL: \\ LECTURA Y GIMNASIA EN LA PRIMERA REPÚBLICA
}

\author{
Lucas William Moreira da Silva ${ }^{1}$ \\ Arnaldo Pinto Junior ${ }^{2}$
}

\begin{abstract}
Resumo: Focalizamos a obra Gymnastica nas aulas (BARAGIOLA, 1895) para discutirmos concepções do ensino escolar no início da República. Dialogando com referências da história cultural, refletimos sobre apropriações de discursos científicos, a ideia do corpo educado e útil à nação.

Palavras-chave: Ginástica; manual didático; Primeira República.
\end{abstract}

\begin{abstract}
We emphasize the work Gymnastica nas aulas (BARAGIOLA, 1895) to discuss conceptions of school teaching in the beginning of the First Republic. Dialoguing with references from cultural history, we reflect on appropriations of scientific discourses, the idea of the educated and useful body to the nation.
\end{abstract}

Keywords: Gymnastic; textbook; First Republic.

Resumen: Nos centramos en la obra Gymnastica nas aulas (BARAGIOLA, 1895) para discutir las concepciones de la enseñanza escolar en los inicios de la República. Dialogando con referencias de la historia cultural, reflexionamos sobre las apropiaciones de los discursos científicos, la idea del cuerpo educado y útil a la nación.

Palabras clave: Gimnasia; libro de texto; Primera República.

\section{Introdução}

Entre o final do século XIX e início do século XX, circulavam pelo Brasil projetos de formação de um novo homem, os quais abordavam desde a importância da educação formal até a correção de hábitos de higiene, gestos, atitudes e comportamentos sociais, principalmente destinados aos grupos populares que não tinham representantes nos elitizados debates (SEVCENKO, 2003). Nesse cenário, ganharam força discursos científicos sobre a higienização e educação do corpo que envolviam, por exemplo, concepções de infância, vida doméstica e espaços coletivos (PYKOSZ; TABORDA DE OLIVEIRA, 2010). Também procurando legitimar suas posições políticas, intelectuais comprometidos com a constituição de uma nova ordem do corpo e do cidadão republicano fizeram uso da escola, uma instituição símbolo para os defensores da modernidade.

Dentre reformulações educacionais implementadas na época, questões como a função política da escola e a seleção cultural para os níveis de ensino são compreendidas como formas discursivas de intervenção social e de elaboração de práticas (SOUZA, 1998). No campo da história da disciplina Educação Física, Góis Jr. e Batista (2010) investigaram um ideário biológico sobre a realidade alinhado a concepções liberais no currículo da Escola Normal de

\footnotetext{
${ }^{1}$ Universidade Estadual de Campinas.

${ }^{2}$ Universidade Estadual de Campinas.
} 
São Paulo após a Reforma Caetano de Campos, em 1890a, o qual se estendeu aos materiais destinados à instrução pública, como no caso dos manuais didáticos.

No âmbito de disputas na defesa da ginástica nas escolas primárias, o presente trabalho discute seu ensino no Brasil nos anos iniciais da Primeira República focalizando o manual didático intitulado Gymnastica nas aulas: manual theorico-pratico dedicado ao professorado para o ensino elementar de exercicios militares e gymnasticos, escrito pelo professor Manoel Baragiola e publicado em São Paulo pela J. B. Endrizzi \& Comp. no ano de 1895.

Considerando os ideais republicanos impressos em produções escolares da época, há indícios que as propostas pedagógicas traçam caminhos complexos, para além de uma educação física racional, versando sobre a conservação ou regeneração de um corpo útil à nação e ao capital. Observamos o papel das auto-regulações destacado pela escola, o qual conferia ao corpo uma prática moderada, higiênica e cívica, prescrições com sentidos de ordem e disciplina. Contudo, nos questionamos em que medida o manual se alinhava a estes preceitos a fim de contribuir para a constituição da ginástica e exercícios militares na escola e de que modo eram selecionados ou segregados certos caminhos de conhecimento sobre o corpo.

\section{Trajetórias do professor italiano e o conteúdo de seu manual}

Tratamos agora dos locais de atuação do professor Manoel Baragiola em terras nacionais. Por meio das menções encontradas em periódicos do estado de São Paulo a seu respeito, temos um indicativo de que Baragiola mantinha contato com alguns redatores locais e já era reconhecido como professor de ginástica e esgrima e pela sua atuação docente (CORREIO PAULISTANO, 1890a). Estas atividades também ocorriam em forma de apresentações e exibições em espetáculos e teatros, como o Teatro Provisório, Teatro Rink, Teatro Minerva e Frontão Paulista, duelando com outros professores a exemplo de Panizza, Vassela, Cristole e Ferreto (CORREIO PAULISTANO, 1890b; 1891).

"Diplomado pela escola Magistral de Educação Physica de Turim" (O COMMERCIO DE SÃO PAULO, 1909, p. 3), Baragiola atuou no Ginásio da capital paulista (nomeação publicada no Correio Paulistano no dia 28 de junho de 1893) para reger os cursos de ginástica e exercícios militares, os quais também ministrou na Escola Normal e na Escola Modelo da mesma cidade. Conforme o periódico Correio Paulistano de 22 de agosto de 1891, Baragiola se instalou neste período em São Paulo, onde abriu um gabinete de ginástica e esgrima na Rua Quintino Bocayuva. A seguinte notícia destaca o ofício de sua profissão e cita um trabalho impresso que precedeu o livro analisado neste artigo: "O professor Baragiola offereceu-nos hontem um exemplar de trabalho seu, illustrado com muitas figuras e referente à gymnastica applicada nas escolas e na esgrima, trabalho que o recommenda para o ensino" (CORREIO PAULISTANO, 1891, p. 1).

O excerto não se refere a Gymnastica nas aulas, pois esta publicação é datada de 1895. Como o trabalho mencionado na notícia não foi encontrado nos arquivos consultados no decorrer da pesquisa, inferimos que se trata de uma versão inicial da obra em questão. Em Gymnastica nas aulas, Baragiola explicitou uma preocupação em organizar métodos destinados ao ensino de ginástica de caráter nacional, a exemplo de intelectuais e professores europeus, como Schreber, Domingos Nascimento, Pedro Manoel Borges, Antônio Martiniano Ferreira, Paulo Lauret, Arthur Higgins, Ludvig G. Kumlien e Caldas e Carvalho. Schreber é um dos autores mais citados em seu livro, devido a sua obra Gymnastica domestica, médica e hygiênica ser a primeira iniciativa no Brasil a "embasar a prática da ginástica por meio da consulta de livros" (PUCHTA, 2015, p. 19).

Sua jornada nas escolas paulistas se encerra, como indica uma publicação no Correio Paulistano, onde "Por decreto de ontem foi aposentado o sr. Manuel Baragiola, professor de 
ginástica e exercícios militares da Escola Normal da Capital e do Ginásio do Estado" (CORREIO PAULISTANO, 1916, p. 2), falecendo em 19 de agosto de 1936 (GOLOMBEK, 2016).

A primeira reforma no período republicano da instrução pública do estado de São Paulo, de 1892, apresentou a ginástica junto ao ensino de exercícios manuais e militares apropriados à faixa etária e ao sexo masculino e feminino. Ela estava na grade tanto do ensino comum das escolas preliminares e complementares, quanto na formação de professores (SÃO PAULO, 1892).

A respeito do processo histórico, onde tratamos dos saberes e práticas da educação física destinadas ao ensino preliminar, consideramos os apontamentos de Souza (1998) ao analisar os programas de ensino, matéria-prima das atividades escolares. A autora descreve a semelhança das práticas registradas pelos diretores dos grupos escolares nos relatórios da Escola-Modelo Caetano de Campos. Em relação ao ensino de ginástica:

Os exercícios militares deveriam começar pelas primeiras posições; exigir presteza e rapidez dos movimentos e não admitir o menor ato de indisciplina. Os alunos que mais se distinguissem deveriam ser graduados nos postos militares para gravar no espírito das crianças a necessidade de hierarquia militar (SOUZA, 1998, p. 202).

A noção e o domínio, então, das posições do corpo as quais as crianças deveriam realizar faziam parte desta ginástica educativa. Dimensões físicas, de presteza, rapidez dos movimentos, estavam também diretamente ligadas ao senso de indisciplina, caso não fossem cumpridas corretamente. Outra marcante característica é a adoção do mérito a quem se saísse melhor nas atividades, no intuito de representar moral e culturalmente, de certa maneira, a necessidade da hierarquia militar.

Contudo, havia uma racionalidade que apoiava tais pressupostos. Ao discutirem sobre a ginástica como disciplina curricular inserida na Escola Normal de São Paulo (posteriormente denominada Escola Estadual Caetano de Campos), Góis Jr. e Batista (2010) traçam uma narrativa dos projetos de cunho positivista e republicanos de construção de um ideário racional e científico sobre o corpo em fontes pesquisadas no acervo histórico da própria escola.

Segundo os autores, são relatadas as relações de igualdade da disciplina de ginástica com as demais, pois quem a administrava era nomeado professor ou professora, e possuíam provas finais. Contudo, essa relação não ocorria no salário desses profissionais, evidenciando uma desvalorização do trabalho que exerciam. Quem a valorizava eram seus defensores, que escreviam artigos e colunas em periódicos, em especial na Revista de Ensino, onde Baragiola também se pronunciava, sob o discurso da educação integral. Neste periódico, o professor publicou um artigo intitulado Ginástica Moderna, em 1908, no qual, apesar da divergência com o manual de 1985, por defender jogos ao ar livre e ginástica com aparelhos, se pauta constantemente na defesa de uma educação física moderna.

Em relação a esta publicação, Souza (1998) aborda a prática educativa e suas sistematizações defendidas por Baragiola:

O caráter da ginástica brasileira deve ser eminentemente educativo-militar, mas deve dar uma grande margem aos jogos ao ar livre. Um país que não tem o serviço militar obrigatório deve dar este ensino nas escolas, e isso só se pode obter com uma ginástica militar bem dirigida. Não é só conhecendo as evoluções militares que um aluno será mais tarde um bom guarda-nacional; é sabendo manejar com facilidade uma carabina, que o aluno terá obtido um bom resultado físico. Para isso precisa o concurso da ginástica, para que ele possa suportar o peso da arma, e dos jogos ao ar livre, para que possa resistir às marchas (REVISTA DE ENSINO apud SOUZA, 1998, p. 204-205). 
A última parte do fragmento acima nos leva ao discurso de militarização dos corpos e à educação das sensibilidades. Ensinar aos alunos, e não às alunas, a suportar o manejo e o peso das armas e a resistir a extensas marchas às quais seriam submetidos caso entrassem para o serviço militar, fazia parte de um projeto de educação dos corpos infantis na escola. Com tal conhecimento, seria possível demonstrar à sociedade moderna que o estudante não só poderia realizar os exercícios, mas que amava suportá-los. Nas propostas em seu livro didático, essa pretensa educação fica ainda mais clara.

Presente como forma de cultura material da escola, Gymnastica nas aulas possui 83 páginas e 50 figuras numeradas, as quais eram ilustrações de alguns dos 207 exercícios propostos. A linguagem do livro possui uma dimensão prescritiva e simbólica, dotada de referências europeias, a respeito de Ling, Obermann, Angerstein e Schreber, além do caráter militar que é expresso já no subtítulo "manual theorico-pratico dedicado ao professorado para o ensino elementar de exercicios militares e gymnasticos". Em sua dimensão simbólico-cultural, tal ensino deveria ter por fim o "desenvolvimento harmônico de todas as partes do corpo e o recreio do espírito" (BARAGIOLA, 1895, p. 17), defendendo, portanto, uma forma específica de educação do corpo.

O livro é dividido em uma parte teórica, antecedida de um prólogo, e outra prática, mais extensa. Neste prólogo, Manoel Baragiola dedica-o ao professorado atuante no ensino das disciplinas de ginástica e exercícios militares. Contudo, deixa claro que não se trata de um trabalho novo: "Elle não é senão o resultado do estudo de várias obras allemães, italianas, francezas, suecas, acompanhando especialmente as indicações das de Ling, Oberman, Angerstein, Schreber, e observando fielmente as vozes de commando adoptadas no exercito brasileiro" (BARAGIOLA, 1895, p. 3).

Na parte teórica, Baragiola expõe a dificuldade que o professorado vinha enfrentando para ministrar as aulas de ginástica nas escolas, e a necessidade de um programa uniforme: "Era necessário, porém, um livro que indicasse aos professores um programa a seguir, um sistema uniforme, para que além dos resultados fisiológicos que esta parte da educação produz, possam também preparar seus alunos para poderem ser úteis a si e à Pátria" (BARAGIOLA, 1895, p. 3).

Descansar o espírito e compensar o esforço mental das crianças para que voltassem com mais ímpeto aos seus estudos, eram proposições assumidas por Baragiola. Tal qual a escrita, a ginástica seria um dos primeiros passos para a educação do corpo, iniciando os meninos nos exercícios militares, e as meninas nas regras dessa prática, tornando seus corpos úteis à pátria.

\section{Movimentos teóricos e o desenvolvimento harmônico do corpo}

No decorrer da parte teórica, o professor indica a importância que deve se dar ao ensino da ginástica educativa, transpondo-a primeiramente como necessidade de sobrevivência natural do homem. Antes de ser reduzida a um sistema racional, escreve que "somente os gregos preocuparam-se com o exercício e o desenvolvimento da força física para o estabelecimento de uma harmonia entre as faculdades mentais e corporais" (BARAGIOLA, 1895, p. 6).

Ainda dá ênfase aos denominados promotores da educação física no século XIX, todos europeus, e indica as finalidades da ginástica racional, a qual teria em seu aspecto uma utilidade moral, a prestação de serviços às eventualidades da vida e resultados fisiológicos. Nesse último trecho, podemos notar outros fins para além do biológico que a ginástica prescritiva por Baragiola trazia. Entre a execução facilitada de todos os membros, aumento da oxigenação muscular, circulação, força e resistência e o desenvolvimento harmônico dos sistemas orgânicos, há uma clara pretensão de retificação do corpo, "e por isso o ginasta cresce com formas proporcionais e estéticas" (BARAGIOLA, 1895, p. 10). 
Nas discussões sobre os processos de educação do corpo, Soares e Fraga (2003) indicam que desde o final dos setecentos e inícios dos oitocentos há um processo de naturalização dos ideais de corpos retilíneos, belos e ágeis. A representação de um corpo educado, seja física ou intelectualmente, era expressa pelo ideal civilizatório.

$\mathrm{Na}$ terceira parte, o espaço para a prática das aulas de ginástica é delimitado entre os bancos das aulas, ou seja, na sala, com regras para que não fossem iniciadas logo após as refeições, e deveria permitir que o ar se renovasse. Seria "rápida, fácil, deleitável e coletiva" (BARAGIOLA, 1895, p. 11), e adaptada à natureza da criança, contudo com a finalidade de sua correta posição do corpo, dando franqueza ao andar e cumprimentar. Ora, se havia uma dita natureza pré-existente nos corpos das crianças, franca, esta não poderia se submeter a exercícios muito difíceis, o que selecionava uma prática controlada e equilibrada. Ainda na mesma parte, Baragiola (1895, p. 11) escreve que a ginástica educativa:

Deve servir para distração do intellecto, alternando os exercicios gymnasticos com as ocupações intellectuaes da escola; deve exercitar o ouvido com o rhytmo, a vista com a precisão e simultaneidade dos exercicios e inspirar sentimentos morais e generosos, combinando os exercicios gymnasticos com canticos faceis. Deve também dar aos alumnos a primeira ideia da ordem, base da vida intellectiva, estetica, moral e economica do homem.

Há uma formação de estruturas de sentimentos morais e intelectuais baseada na prática dos exercícios ginásticos, onde a educação dos sentidos, audição, visão, tato e cinestesia, era manejada para a conservação, ou mesmo criação, de um corpo ciente de princípios de ordem e da vida intelectual, estética, econômica.

$\mathrm{Na}$ quarta parte é mobilizada a prática da ginástica especificamente para meninas. Baseando-se em autores ${ }^{3}$ como Frank, Kloss, Flor, Guts-Muth, Spiess, Clias, Obermann, Gamba, Mantegazza e Angerstein, o autor corrobora diferenças fisiológicas e morais entre meninos e meninas e, novamente, traz à tona os ideais gregos e romanos de educação física da mulher, cabendo à modernidade retomar seu desenvolvimento físico e intelectual pela ginástica. Se limitava a um método ainda mais moderado e especial, na pretensão de eliminar grande parte das enfermidades que atingiam as mulheres, como a anemia, as pressões estéticas pelas roupas e a inatividade muscular. Mas há uma preocupação maior com alunas brasileiras, onde Baragiola adota o método da ginástica sem aparelhos, consistindo quase unicamente em exercicios elementares. Ao final é indicado que os exercícios possíveis de execução pelas meninas são sinalizados com um $M$ maiúsculo.

$\mathrm{Na}$ quinta parte, o canto também é parte constituinte da educação do corpo. Aplicado à ginástica, ele deveria "exercitar o aparelho de phonação, para dar cadencia aos movimentos gymnasticos e mais elegancia na sua execução [...]" (BARAGIOLA, 1895, p. 16). As maneiras que o canto deveria ser aplicado às aulas eram duas: " $1^{\circ}$ Acompanhando com a voz os movimentos proprios; $2^{\circ}$ Acompanhando os movimentos dos outros gymnastas" (BARAGIOLA, 1895, p. 17). Aqui também são elencados outros autores de obras gymnasticas, como Platão, Tomaseo, Amorós, Fröbel, para sustentar a ideia de que ginástica e canto nunca deveriam se separar. A defesa do canto serviria para inspirar aos gymnastas "o amor á Pátria, as boas ações e além disso, ordem, disciplina e elegancia nos exercicios" (BARAGIOLA, 1895, p. 16). Ao traduzir especialmente um trecho da obra de Amorós, Gymnastique et morale, uma educação dos sentidos é explicitada novamente:

\footnotetext{
${ }^{3}$ Não há citação de nenhuma referência feminina na obra de Baragiola, ainda que houvesse registros de professoras de ginástica neste período, como Maria Moratti (GÓIS JR.; BATISTA, 2010).
} 
Todos os cantos são compostos de palavras, de melodia, de harmonia e de rhytmo, e eu, aproveito-me destes quatro meios para inspirar a meus discipulos; por meio das palavras, boas idéas e bons sentimentos; por meio da melodia e da harmonia, bom gosto; por meio do rhytmo os habituo a precisão, á ordem, a regularidade em todas as acções da vida (BARAGIOLA, 1895, p. 16).

Bons sentimentos e boas ideias, bom gosto, precisão, ordem e regularidade às ações da vida eram objetivos a serem alcançados por esta educação do canto aplicado à ginástica. Há neste trecho e em toda a obra devidas práticas para formação do homem integral, ou seja, que tenha os aspectos físico, moral e intelectual desenvolvidos agora em nome da modernidade ${ }^{4}$. Isto porque, educandose os sentidos, as sensibilidades, a vontade, estaria formado o cidadão útil à República.

Na sexta e última subdivisão da parte teórica, são descritas algumas regras para se lecionar a ginástica racional. O desenvolvimento harmônico de todas as partes do corpo e o recreio do espírito, eram finalidades essenciais para seu ensino; o vestuário não deveria ser apertado e as meninas não poderiam praticá-la de colete ou salto alto; as aulas iniciariam com exercícios militares e terminariam com exercícios ginásticos, estes, com muitas pausas e de duração de 15 minutos; os movimentos seriam explicados, demonstrados e comandados pelo professor ou professora; deveria ser empolgante a alunos e alunas, e seriam exigidas energia, precisão e graça na sua execução, com variações diárias de exercícios e combinações; o professor necessitaria de conhecimentos de anatomia, fisiologia e higiene; aos alunos com defeitos físicos ou vícios orgânicos era prescrito a consulta a um médico, para serem excluídos das aulas ou praticar exercícios especiais.

\section{Movimentos práticos: uma questão de ordem}

A parte prática era subdividida em exercícios militares, marchas na aula, formação de cadeias, tomar distâncias, posições ginásticas fundamentais, ginástica pulmonar (respiratória), movimentos da cabeça, do tronco, das extremidades superiores e inferiores, passos rítmicos, movimentos de ginástica aplicada e combinações. Iniciada com uma série de exercícios militares, "adotados do exército brasileiro [...] devem ter por fim habituar o aluno a compreender mais tarde os comandos militares mais difíceis" (BARAGIOLA, 1895, p. 21). São apresentados os termos militares fileira, fila, distâncias e intervalos, e, especificamente para os meninos, frente, retaguarda, direita, esquerda, indicar as partes principais do corpo e as vantagens desta disciplina. Em todos, eram exigidos sentidos de ordem e disciplina, acompanhando todo o grupo, pois era uma prática coletiva.

O autor então descreve o ensino sem arma, iniciando com os exercícios preliminares. A posição de sentido serviria "para começarem os exercícios ginásticos ou fazerem continência" (BARAGIOLA, 1895, p. 22). Esta posição é prescrita também para as formaturas militares, descrita da seguinte forma:

Consiste em ter os calcanhares na mesma linha e unidos, os pés formando um ângulo agudo, os joelhos direitos, o ventre recolhido, o tronco a prumo sobre os quadris, o peito avançado sem afectação, os braços cahidos em posição natural, as mãos abertas, os dedos unidos, a cabeça erguida e o olhar frente (BARAGIOLA, 1895, p. 22).

\footnotetext{
${ }^{4}$ A preocupação à educação integral alinhada aos discursos da educação física esteve presente desde o período Monárquico, porém na transição para a República, ela é mais voltada à formação do cidadão republicano ativo (PUCHTA, 2015).
} 
A busca pela consciência do alinhamento das partes do corpo e do olhar, remete a uma presente educação dos sentidos. Um genuíno aluno da escola republicana possuía um tronco aprumado, ventre recolhido e movia-se com o olhar para frente, e tais sentidos cinestésicos formavam sensibilidades em relação ao corpo em movimento e repouso. Não era utilizado no início ocasionalmente, mas sim para que estas percepções se mantivessem durante toda a prática. A angulação dos pés e a posição correta da cabeça é um exemplo desta disciplina com o próprio corpo, prescrita não somente neste primeiro comando, mas também em descansar, descansar a vontade, nos exercícios das voltas, marchas e posições ginásticas fundamentais, onde são encerrados os exercícios militares e iniciados os exercícios ginásticos.

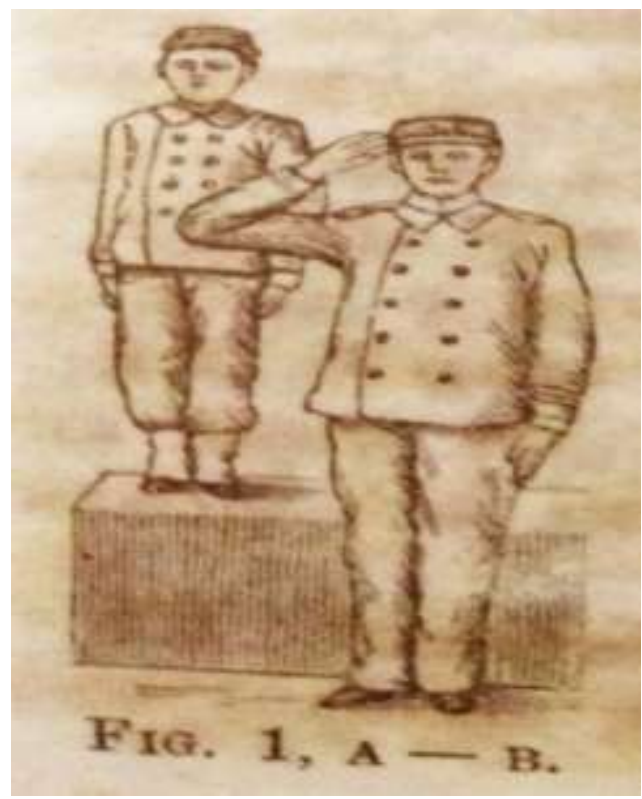

Figura 1. Primeiro exercício preliminar Sentido - Fonte: Acervo da Escola Estadual Caetano de Campos

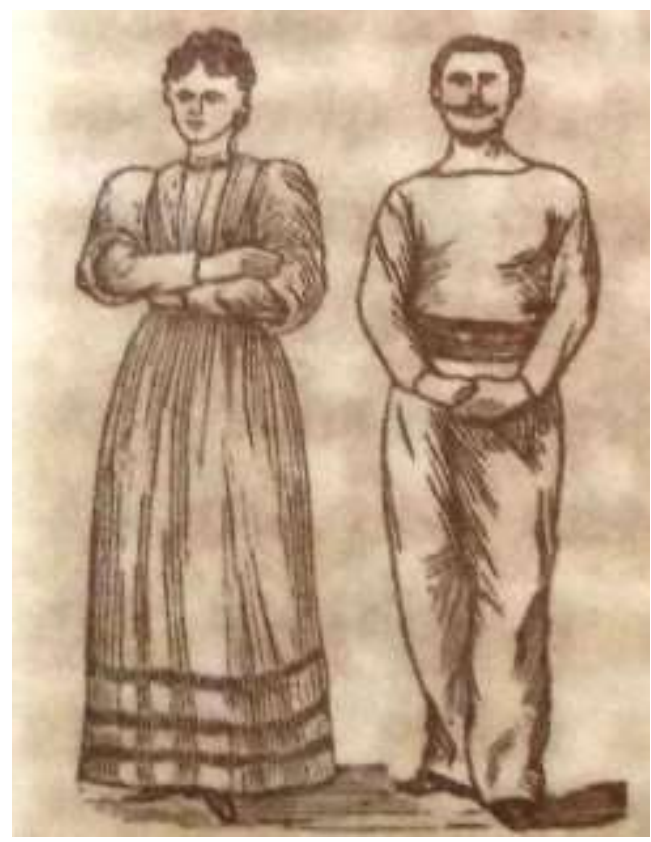

Figura 2. Quinto exercício preliminar Descansar a vontade - Fonte: Acervo da Escola Estadual Caetano de Campos 
Descansar a vontade permitia o descanso mais livre e prolongado, somente após o comando, porém sem perder o alinhamento descrito no primeiro exercício. Sua volta seria obedecida ao comando firme. Em seguida, são apresentadas as voltas, tipos de marchas, marchas na aula, esta última precedida de uma frase de Lévis, "Établisser l'ordre, l'habitude, l'entretiendra"5. Nas partes seguintes estão os exercícios de formação de cadeias, as ordens de formação de filas, tomar distâncias, e posições "gymnasticas fundamentaes".

Na sexta parte, a Gymnastica Pulmonar ou respiratória, possui novamente uma referência ao autor Schreber. Esta se refere à natureza do seu método, exemplificada em um parágrafo que Baragiola destaca como epígrafe do capítulo 7, intitulado Movimentos da cabeça: "Convém ter em conta a natureza dos movimentos, o modo de executá-los, a duração de cada exercício, e a frequência dos exercícios executados, ou seja, em duas palavras, a conveniência individual da natureza e das somas dos movimentos" (BARAGIOLA, 1985, p. 46).

$\mathrm{Na}$ descrição destes movimentos, o corpo aparece como fragmentado, divididos em movimentos de cabeça, das extremidades superiores e inferiores, equilíbrios, passos rítmicos preparatórios para a dança, exclusivamente às meninas, movimentos de ginástica aplicada, divididos em exercícios preliminares de natação, exercícios de canotagem e exercícios diversos. Em sua última parte, são prescritas combinações de exercícios elementares.

Já os exercícios não permitidos para as meninas, estão entre eles, membros inferiores à frente e ao lado, elevações frontais, laterais e oblíquas de ambas as pernas, e abrir lateral e simultaneamente as extremidades inferiores, circunduções para dentro e para fora, flexões das coxas, flexões e extensões laterais e oblíquas simultâneas dos membros inferiores, equilíbrios sobre saltos e sobre a ponta de um pé.

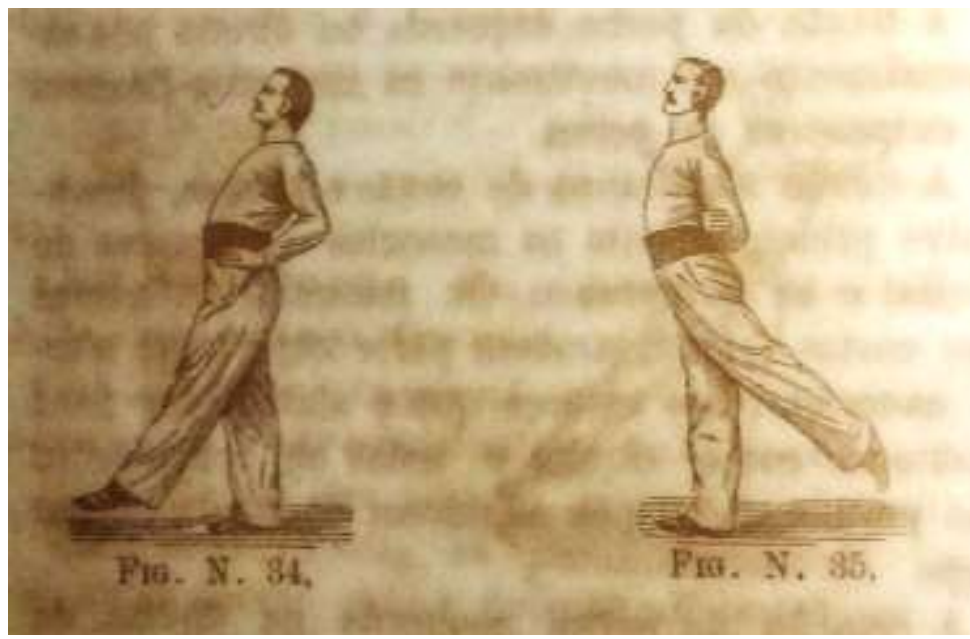

Figura 3. Exercícios perna esquerda à frente e perna esquerda a retaguarda, da esquerda para a direita respectivamente (permitidos às meninas) - Fonte: Acervo da Escola Estadual Caetano de Campos

\footnotetext{
${ }^{5}$ Tradução livre do original francês: Estabeleça a ordem, o hábito a manterá.
} 


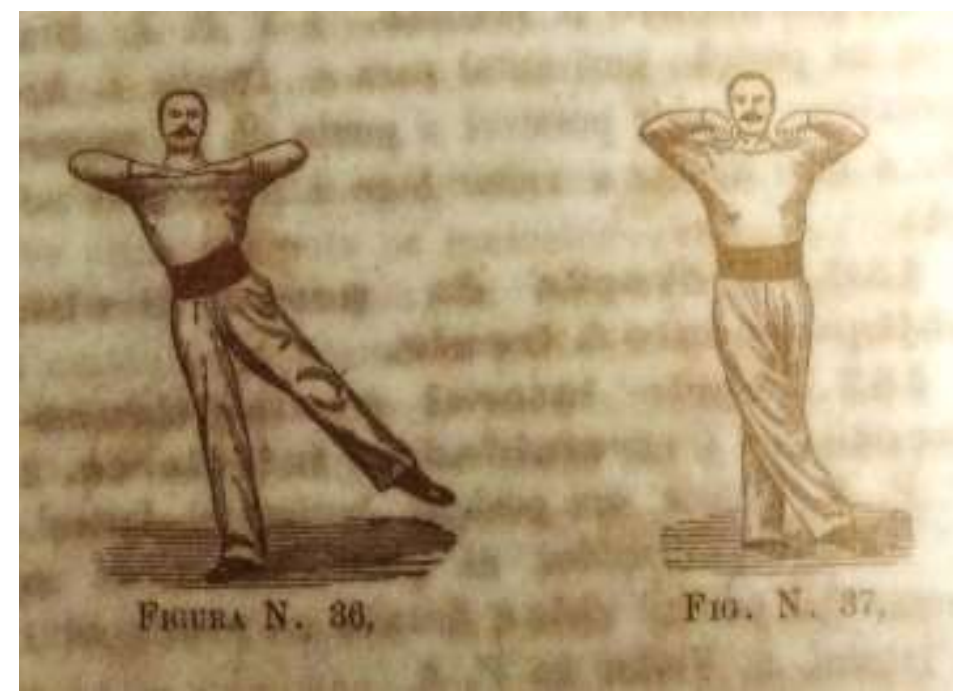

Figura 4. Exercícios perna esquerda lateral e perna esquerda oblíqua à frente, da esquerda para a direita respectivamente (não permitidos às meninas) - Fonte: Acervo da Escola Estadual Caetano de Campos

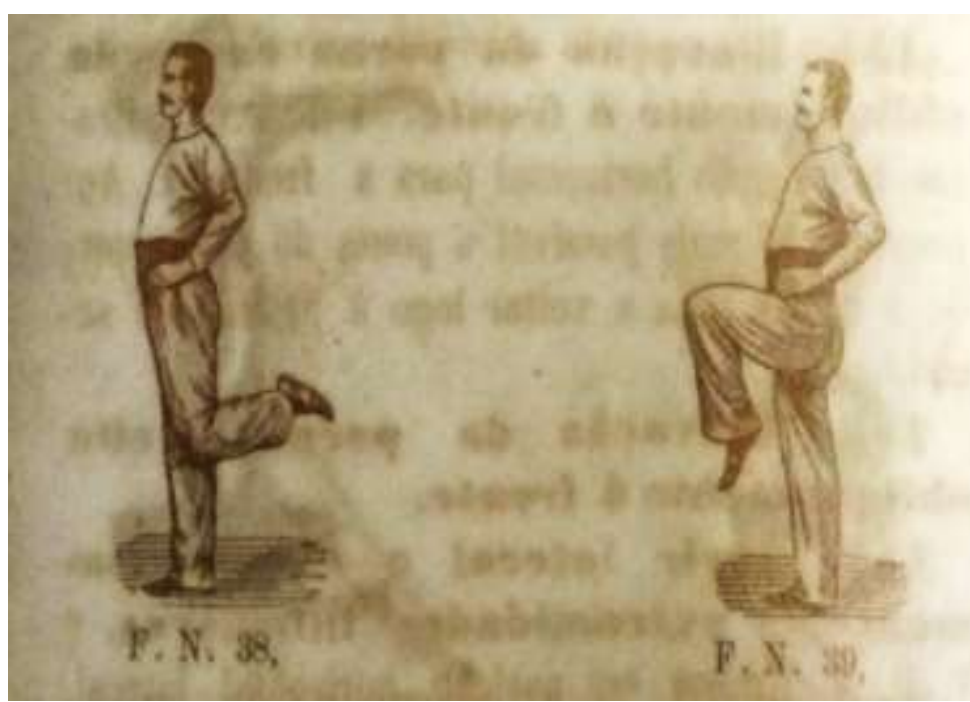

Figura 5. Exercícios Flexão da perna esquerda (à esquerda), permitido às meninas, Flexão da coxa esquerda (à direita), não permitido às meninas - Fonte: Acervo da Escola Estadual Caetano de Campos 


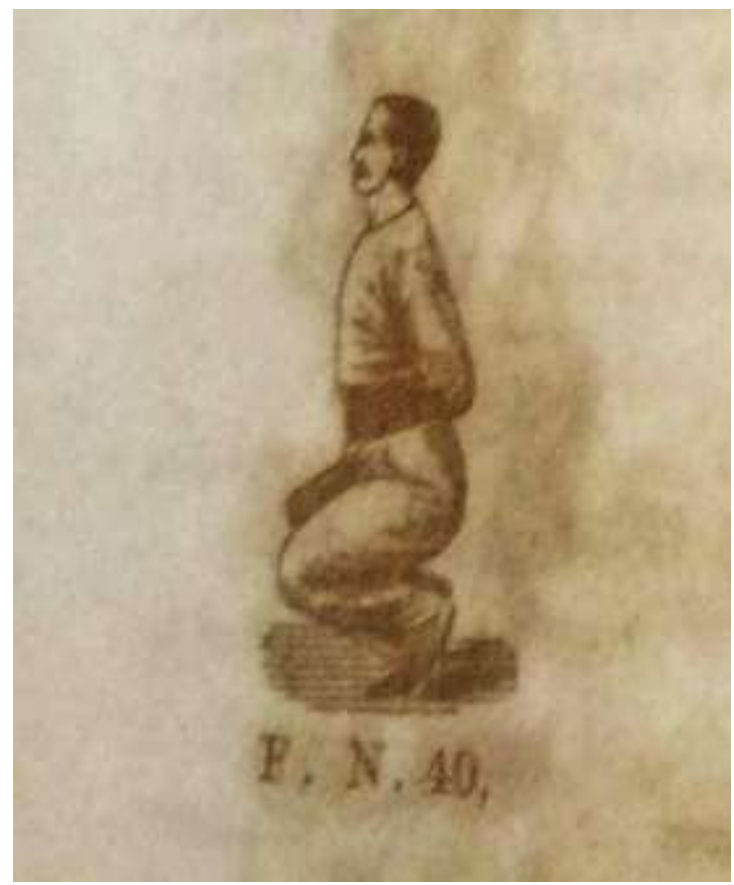

Figura 6. Exercício Flexão simultânea de coxas e pernas, não permitido às meninas Fonte: Acervo da Escola Estadual Caetano de Campos

A forma específica destes movimentos, os quais indicavam que as pernas devem se afastar ou se cruzar, eram inadequados às meninas, pois, segundo Baragiola, sua dignidade não deveria ser ofendida pela ginástica na escola.

Também era direcionado somente às meninas, passos rítmicos preparatórios para a dança, os quais, 4 exercícios para o meio passo, 3 para os passos compostos, passos saltando (não são descritos nesta seção) e a recomendação de que se combine os passos com o movimento dos braços. Aos sentidos, lhe cabiam as noções de agilidade e elegância ao corpo. Neste sentido, Gleyse e Soares (2008) ao debaterem questões relacionadas à educação do corpo feminino em manuais escolares franceses, escrevem:

O mito da mulher fraca presente em todos os textos, de um modo visível ou não, é assim apreendido pelos alunos. Nessa mesma ótica, o mito de uma mulher voltada à estética e à doçura está permanentemente superexposto neles [...]. Todavia, ao falar a favor das turmas mistas [...], exceto quando se afirma que estas são nocivas à aprendizagem, poderíamos perguntar-nos se essa não seria uma maneira disfarçada de "segregação positiva das moças". Essa segregação poderia, finalmente, tornar-se, em certos domínios, uma estigmatização feminina (GLEYSE; SOARES, 2008, p. 153).

Bem como afirmam as autoras, o fato das propostas de aulas mistas acontecerem nas escolas, algo presente no manual de Baragiola, levavam à tona uma segregação racional entre meninos e meninas, baseadas na moral e na ciência positivista.

$\mathrm{Na}$ décima segunda parte, há exercícios denominados movimentos de gymnastica applicada, subdivididos em exercícios preliminares de natação, exercícios de canoagem e exercícios diversos. Não há a indicação preliminar de que esta sessão possa ser ensinada a meninas. Os cinco exercícios para natação, em terra, configuram-se em movimentos de natação dos membros superiores e inferiores. Os dois únicos exercícios para canoagem simulam movimentos de remar para frente e à retaguarda. Os exercícios diversos são análogos a 
movimentos de velocípede, ao ato de serrar, ceifar, rachar lenha e marcar passos acelerados, em concordância aos exercícios militares. Cada um possui recomendações milimétricas da posição do corpo, como por exemplo "separar as mãos uns quinze centímetros uma da outra" (BARAGIOLA, 1895, p. 76), ou noções das partes do corpo, como unhas voltadas em baixo (sic), polegar para dentro, palmas da mão para dentro etc. Além da noção prévia de posições militares, e com a audição atenta ao comando alto, o qual indica o término da atividade.

Por fim, há a combinação de exercícios elementares, marcados com a voz ou batendo com as mãos, e permitia que o professor ou professora criasse novas aulas e atendessem a uma das regras do método de ensino, ou seja, variar os exercícios todos os dias para que as crianças gostem e tenham vontade de executá-los. A ordem de execução se divide em tempos contínuos, tempos determinados, repetições e combinações e o modo de execução deveria se relacionar com a ação de um segmento do corpo em relação ao outro, ao mesmo tempo ou alternadamente. Esta era a última sessão da parte prática de Gymnastica nas aulas.

Entre os discursos dos autores de manuais ginásticos apresentados até agora, há em comum o ideário de um indivíduo saudável, que deveria estar ciente de uma interpretação do que sentia entre corpo e o ambiente externo. Contudo, pelas diferenças de contextos, tempos e lugares, a obra de Baragiola carrega um alinhamento destas preocupações com a regeneração do homem novo, útil à Pátria.

Ao longo de toda a obra são dadas inúmeras recomendações de uma educação física, moral e cívica na escola. Compreendemos que, estando as disciplinas de ginástica e exercícios militares na legislação escolar, em uma época marcada por reformas e ideais de modernização da sociedade e de seus corpos, fomentou a produção didática de Baragiola. Nesta esteira, saberes e práticas se constituíam e eram constituídos por sujeitos que sentiam, mas também educavam sentidos, para que se internalizasse uma racionalidade que não era habitual nas camadas populares. São caminhos onde a ginástica como disciplina escolar passou em seu lento e gradual processo de consolidação até a institucionalização da Educação Física.

\section{Considerações finais}

O Estado de São Paulo e a Escola Normal foram os principais lugares de atuação de Manoel Baragiola. Estar presentes nestes espaços destacava também o professor como importante agente nos processos de transformações da educação física nas escolas paulistas nos anos iniciais da Primeira República. Com Gymnastica nas aulas, há o desejo de influenciar o cenário do ensino pública de ginástica e exercícios militares por parte do autor, alinhado constantemente às preocupações acerca da regeneração do homem novo. Ressaltamos que no contexto brasileiro, esta não foi a primeira tentativa de se organizar a prática da ginástica em um método, nem ao menos era um 'novo desejo', contudo, foi a primeira publicada genuinamente no período da Primeira República, em 1895, na tentativa de homogeneizar seu ensino (PUCHTA, 2015).

As reflexões apresentadas sugerem que a expressão física da ginástica representada no manual se alinhava constantemente aos ideais republicanos, expressadas principalmente nos comandos de ordem militar, nas recomendações higiênicas pautadas em pressupostos científicos e na defesa de uma prática voltada à modernização do país. Havia um sentimento patriótico, de proteção à nação através do vigor físico.

Desse modo, há uma educação nas prescrições no direcionamento do olhar, na propriocepção da posição milimétrica e angular dos pés, na sinestesia, ou seja, nas próprias noções de movimento, transferência de peso, equilíbrio e posição do corpo nos diferentes comandos militares como filas, fileiras, tomar distâncias, intervalos, sentido, continência, reverência e até mesmo maneiras corretas de se descansar. 
Os tipos de corpos que se pretendia reproduzir nas crianças eram repletos de um imaginário científico, militarizado e até mesmo segregacionista entre os gêneros, mesmo numa proposta de aulas mistas. Nota-se inúmeros exercícios, em especial os que remetem aos movimentos das pernas, proibidos às meninas e a prática de passos rítmicos voltados apenas para elas, em nome da conservação de sua dignidade.

Neste cenário, livro e autor se inserem em um processo de racionalização e cientifização da ginástica e exercícios militares, e entendemos que suas pretensões, para além do organismo saudável, se baseava na ideia de sua útil conservação à nação, ao trabalho industrial e ao serviço militar. Esta utilidade se alinhava constantemente aos ideais republicanos de ordem, controle das vontades, vigor, moral e civismo. Contudo, salientamos que o referido manual, mesmo pensado e produzido para a escola, possibilita inúmeras leituras singulares. Apesar da presença de um sólido método de ensino apresentado por Baragiola, há de se considerar que a educação física na escola também era ministrada por circenses e acrobatas, os quais possuíam fortes influências do circo e seus saberes.

\section{Referências}

BARAGIOLA, Manoel. Gymnastica nas aulas: manual theorico-pratico dedicado ao professorado para o ensino elementar de exercicios militares e gymnasticos. São Paulo: J. B. Endrizzi \& Comp., 1895.

CORREIO PAULISTANO. São Paulo, 05 de dezembro de 1890a, ano XXXVII, n. 10275, p. 1.

CORREIO PAULISTANO. São Paulo, 12 de dezembro de 1890b, ano XXXVII, n. 10281, p. 3.

CORREIO PAULISTANO. São Paulo, 22 de agosto de 1891, ano XXXVIII, n. 10483, p. 1.

CORREIO PAULISTANO. São Paulo, 15 de março de 1916, n. 18919, p. 2.

O COMMERCIO DE SÃO PAULO. São Paulo, 20 de maio de 1909, ano XVI, n. 1027, p. 3.

GLEYSE, Jacques; SOARES, Carmen Lúcia. Os manuais escolares franceses de educação física, de higiene e de moral seriam sexistas? (1880-2004). Educação e Sociedade, Campinas, v. 29, n. 102, p. 137-156, abr. 2008.

GOLOMBEK, Patrícia. Caetano de Campos: a escola que mudou o Brasil. São Paulo: EdUSP, 2016.

GÓIS JUNIOR, Edivaldo; BATISTA, José Carlos Freitas. A introdução da gymnastica na escola normal de São Paulo (1890-1908). Movimento (ESEFID/UFRGS), Porto Alegre, v. 16, n. 3, p. 69-85, mai. 2010.

PUCHTA, Diogo Rodrigues. A escolarização dos exercícios físicos e os manuais de ginástica no processo de constituição da educação física como disciplina escolar (1882-1926). 2015. 285f. Tese (Doutorado em Educação) - Faculdade de Educação, Programa de Pós-Graduação em Educação, Universidade Federal de Minas Gerais, Belo Horizonte, 2015.

PYKOSZ, Lausane Correa; TABORDA DE OLIVEIRA, Marco Aurélio. A higiene como tempo e lugar da educação do corpo: preceitos higiênicos no currículo dos grupos escolares do estado do Paraná/Brasil. Historia de la educación, Salamanca, n. 29, p. 259-282, 2010. 
SÃO PAULO. Lei n. 88, de 08 de setembro de 1892. Reforma a instrucção publica do Estado. Disponível em: https://www.al.sp.gov.br/repositorio/legislacao/lei/1892/lei-88-08.09.1892.html. Acesso em: 28 abr. 2021.

SEVCENKO, Nicolau. Literatura como missão: tensões sociais e criação cultural na Primeira República. 2. ed. São Paulo: Companhia das Letras, 2003.

SOARES, Carmen Lúcia; FRAGA, Alex Branco. Pedagogia dos corpos retos: das morfologias disformes às carnes humanas alinhadas. Pro-posições, Campinas, v. 14, n. 2, p. 77-90, mai./ago. 2003.

SOUZA, Rosa Fátima de. Templos de civilização: a implantação da escola primária graduada no Estado de São Paulo (1890-1910). São Paulo: Ed. UNESP, 1998.

\section{Sobre os autores}

Lucas William Moreira da Silva. Graduando nos cursos de Bacharelado e Licenciatura em Educação Física da Universidade Estadual de Campinas, bolsista de Iniciação Científica pelo Conselho Nacional de Desenvolvimento Científico e Tecnológico (CNPq) e membro do Grupo de Pesquisa Memória, História e Educação da Faculdade de Educação - Unicamp.

E-mail: lucaswmoreiras@gmail.com.

Arnaldo Pinto Junior. Bacharel e licenciado em História, mestre e doutor em Educação, é professor da Faculdade de Educação - Unicamp, membro do Grupo de Pesquisa Memória, História e Educação, coordenador do Espaço de Apoio ao Ensino e Aprendizagem da Unicamp e diretor da Associação Brasileira de Ensino de História (ABEH).

E-mail: apjfe@unicamp.br. 